\title{
Chemical Changes in Meat Prepared by Using Microwave Compared to Conventional Methods
}

\author{
Shehab T* \\ Department of Food Sciences, Syria
}

Abstract

ISSN: 2640-9208

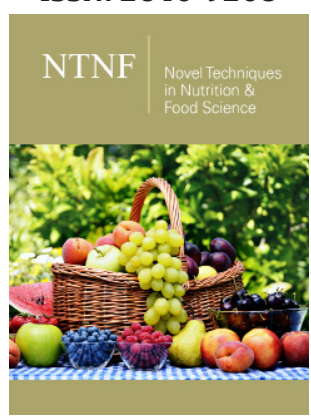

*1Corresponding author: Shehab $\mathrm{T}$ Department of Food Sciences, Syria

Submission: 毕 August 24, 2019

Published: 睯August 29, 2019

Volume 4 - Issue 3

How to cite this article: Shehab $\mathrm{T}$. Chemical Changes in Meat Prepared by Using Microwave Compared to Conventional Methods. Nov Tech Nutri Food Sci. 4(3).NTNF.000587.2019. DOI: 10.31031/NTNF.2019.04.000587

Copyright@Shehab T, This article is distributed under the terms of the Creative Commons Attribution 4.0 International License, which permits unrestricted use and redistribution provided that the original author and source are credited.
Keywords: Chicken; common carp fish; Cooking methods; Microwave; Chemical composition; fatty acids; Amino acids

\section{Opinion}

The study was carried out to determine the effect of microwave cooking in nutrients components, fatty acids and amino acids composition of white and black chicken meat (breast \&thigh) and Common Carp fish (Cyprinus carpio) as compared with some conventional methods, i.e. boiling, pressure and roasting for chicken meat, frying and roasting for common carp fillets . The following results were obtained: Uncooked chicken breast meat samples had higher contents of moisture, protein, ash, $\mathrm{P}, \mathrm{K}$ and $\mathrm{Mg}$, but lower contents of fat, $\mathrm{Na}, \mathrm{Ca}, \mathrm{Fe}, \mathrm{Zn}$ and $\mathrm{Cu}$ than uncooked thigh meat. The percentage of saturated fatty acids (SFA) of chicken meat (breast and thigh) was higher than the percentage of unsaturated fatty acids (USFA). The oleic acid, linoleic and palmitoleic were the major unsaturated fatty acids of two kind of chicken meat. Meanwhile, palmitic and stearic acids were predominating saturated fatty acids. However, the percentage of unsaturated to saturated fatty acids was higher in the thigh than in the breast.

The uncooked chicken meat (white and black) contained the same individual amino acids with slight differences in their amounts. The white chicken meat contained greater amount of serine, histidine, arginine, threonine, valine, methionine, isoleucine, leucine, phenylalanine and lysine, while black chicken meat contained greater amounts of aspartic acids, glutamic acid, glycine, alanine, cysteine and tyrosine. However, uncooked white meat contained more essential amino acids (EAA) and less non-essential amino acids (NEAA) than uncooked black chicken meat. The tyrosine and cysteine acids were the least in the EAA and NEAA, respectively. More ash and tested minerals content $(\mathrm{P}, \mathrm{K}, \mathrm{Mg}, \mathrm{Na}, \mathrm{Ca}, \mathrm{Fe}, \mathrm{Zn}$ and $\mathrm{Cu}$ ) were retained after microwave cooking than other cooking methods for either chicken white or black meat samples. Cooking methods caused slight increase in $\mathrm{pH}$ values.

The percentage of saturated fatty acids increased in meat samples cooked by roasting, but the unsaturated fatty acids had the reverse trend. The percentage of unsaturated to saturated fatty acids decreased in all investigated cooking methods compared to uncooked samples. The different cooking methods caused decreasing in amino acids of all tested chicken meat samples. Marked decrease happened in leucine, tyrosine, phenylalanine and lysine (as EAA) as well as serine, glycine alanine, histidine and arginine (as NEAA). The uncooked common carp fillets contained different percentage of protein, ash, lipids and nutrients minerals $(\mathrm{P}, \mathrm{K}$, $\mathrm{Mg}, \mathrm{Na}, \mathrm{Ca}, \mathrm{Fe}, \mathrm{Zn}$ and $\mathrm{Cu}$ ). The saturated fatty acids formed about one third of total fat and the palmitic acid was the major saturated fatty acid followed by stearic and meristic acids. On the other hands, the USFA eequivalent to almost twice of SFA, there was a high percentage of monounsaturated fatty acid (MUSFA) due to high amount of oleic acid. The percentage of fatty acids- $\omega 3$ was higher than fatty acids- $\omega 6$. The amount of essential amino acids were lower than non-essential amino acids, the lysine, leucine and valine were the major acids in EAA and the amount of methionine was the least in the EAA, while the glutamic, aspartic acid and glycine were the predominate in the NEAA and the histidine acid was the least in the NEAA. The cooking methods effected in moisture content of common carp fillets and the frying 
samples had lower moisture content than that of other cooking methods. The least moisture lost was in microwave-cooked fillets. The ash content was high in microwave-cooked samples compared with other cooking methods. On the other hands, the cooking methods resulted in decreasing amounts of $\mathrm{P}, \mathrm{K}, \mathrm{Mg}$, and $\mathrm{Na}$. The microwave method excelled to maintain the quantity of $\mathrm{P}, \mathrm{K}, \mathrm{Mg}$ and Na compared with other cooking methods. While the frying method caused a significant decrease in these elements.

The percentage of saturated fatty acids was increased in roasting, microwave methods and the percentage of MUSFA was decreased, while the percentage of MUSFA increased in frying method and there was a notable increasing in oleic acid. There was a decreasing in percentages of EPA, DPA and DHA in frying methods and the content of PUSFA $\omega 3$ was higher than content PUSFA $\omega 6$ but the total of PUSFA and PUSFA 33 were decreased in all cooking methods excepted microwave method. The frying method caused a big decrease in levels of USFA- $\omega 3$, DHA, DPA and $\omega 3 / \omega 6$ compared with microwave method. The percentages of total amino acids, essential amino acids and non-essential amino acids of all cooked carp fillets were decreased in all tested cooking methods compared with uncooked samples, noting that microwave-cooking method has maintained the largest amount of amino acids. 